\title{
ANÁLISE DO VALOR DAS MULTAS APLICADAS PARA O CORTE IRREGULAR DE ÁRVORES DE RUA NA CIDADE DE CURITIBA - PR
}

\author{
Luciana Leal ${ }^{1}$, Daniela Biondi ${ }^{2}$, Roberto Rochadelli ${ }^{3}$ \\ (recebido em 22.11.2007 e aceito pra publicação em 17.01.2008)
}

\section{RESUMO}

No contexto ambiental, na maioria das vezes, as multas não correspondem aos valores reais dos bens em questão ou estão super ou subestimadas, trazendo problemas para a sua aplicação. Os critérios para estabelecer os valores das multas são fundamentais. Baixos valores das multas podem induzir ao descumprimento das leis, enquanto altos valores podem ser de difícil aplicação. Neste trabalho foram comparados os valores das multas para corte irregular de árvores isoladas em bem público, estabelecidos empiricamente pela legislação municipal da cidade de Curitiba, com os seus custos de implantação e manutenção. Nos dez casos reais de aplicação de multas avaliados, os valores estabelecidos pela legislação municipal foram inferiores aos custos estimados, com diferença proporcional à idade da árvore.

Palavras-chave: arborização urbana, legislação municipal, Código Florestal de Curitiba, custos de implantação e manutenção de árvores urbanas.

\footnotetext{
1 Engenheira Florestal, M.Sc. Curitiba - PR (luciana_paisagem@yahoo.com.br)

2 Engenheira Florestal, Dra. Professora associada Depto. Ciências Florestais/UFPR, Bolsista Produtividade em Pesquisa - CNPq, Curitiba - PR (dbiondi@ufpr.br)

3 Engenheiro Florestal, Dr. Professor adjunto Depto. Economia Rural e Extensão/UFPR, Curitiba - PR (nashtell@hotmail.com)
} 


\title{
ANALYSIS OF FINES VALUES APPLIED FOR IRREGULAR CUT OF STREET TREES IN THE CITY OF CURITIBA - PR
}

\begin{abstract}
In the environment context, in the most of the times, the fines do not correspond to the real values of the goods in question, or the values are overestimated or underestimated, causing problems for its application. The criteria to establish the fines values are fundamental. Low values of the fines can induce to uncarry law out, while high values can be of difficult application. In this paper the fines values for irregular cut of street trees established subjectively by the district forest laws in Curitiba were compared with the implantation and maintenance costs of the street trees. In the ten real cases of application of evaluated fines, the values established by the law were lower than the estimated, increasing this difference directly proportional to tree age.
\end{abstract}

Key words: urban trees, district forest laws, Código Florestal de Curitiba, implantation and maintenance costs of the urban trees. 


\section{INTRODUÇÃO}

As árvores urbanas são um bem público e, por isso, devem ser protegidas por legislações específicas. Muitas cidades brasileiras apresentam leis específicas de proteção às árvores urbanas, com a definição de multas por danos, corte ou morte de árvores. Nessas leis, no entanto, os valores das multas foram estabelecidos empiricamente, sendo genéricos, sem apresentar uma base científica e concreta. Para Santos (1996), a determinação arbitrária de um valor por unidade arbórea, pelo fato de não seguir nenhum critério econômico embasado em dados concretos, é considerada bastante subjetiva.

Grey \& Deneke (1986) relatam a necessidade de estabelecimento de legislações que visem à proteção da arborização quanto a danos acidentais ou não e de multas aos infratores ou agentes causadores de danos. A determinação dos valores legais das árvores pode ser utilizada em casos de danos por acidentes e veículos; queda por ventos fortes; levantamento prévio para instalação de tubulações de gás, redes elétricas subterrâneas, construção de encanamentos de esgoto ou água e alargamento de estradas; infrações durante construções; levantamento de propriedades e em práticas de podas inadequadas.

Segundo Detzel (1993), a aplicação de multas, indenizações e isenções deve ser estabelecida segundo critérios bem definidos e cujos valores resultem de métodos de valoração de comprovada eficácia e veracidade.

Para as condições brasileiras, segundo Santos (1996), o método de composição de custos de implantação e manutenção seria o mais favorável atualmente para obtenção do valor das árvores, em razão da carência de outras informações básicas sobre as espécies hoje utilizadas na arborização urbana.

Uma das cidades brasileiras que possui legislação própria sobre o corte irregular de árvores em bem público é Curitiba, através do Código Florestal do Município, estabelecido pela Lei no 9.806/2000 (CURITIBA, 2000). O descumprimento às disposições da presente lei sujeitará o responsável ao pagamento de multas que variam de $R \$ 127,20$ a $R \$ 1590,00$, conforme a espécie (nativa, exótica ou exemplar de Araucaria angustifolia) e o diâmetro do indivíduo avaliado (três classes).

Os objetivos da presente pesquisa, em um estudo de caso na cidade de Curitiba, foram comparar os valores das multas, estabelecidas empiricamente pela legislação municipal, com os custos de implantação e manutenção da arborização de ruas e analisar a aplicabilidade da cobrança dos valores das multas fundamentadas nestes custos.

\section{MATERIAL E MÉTODOS}

Como estudo de caso, foi considerada a cidade de Curitiba, capital do Estado do 
Paraná, localizada na região sul do Brasil, na latitude $25^{\circ 2} 5^{\prime} 40^{\prime \prime S}$ e longitude $49^{\circ} 16^{\prime 2} 23^{\prime \prime W}$ (IPPUC, 2007). Esta cidade é destaque nacional por sua arborização urbana, com início de introdução de árvores em suas ruas a partir do século XIX (OBA, 1998) e possuindo atualmente aproximadamente 300 mil árvores plantadas nas vias públicas (REIS, 2006).

Para comparar os valores das multas estabelecidas pelo Código Florestal do Município - Lei no 9.806/2000 (CURITIBA, 2000) com os respectivos custos de implantação e manutenção das árvores de rua foram obtidos em campo casos reais de avaliação. Nos meses de setembro e outubro de 2006, foram obtidos dez exemplos de casos reais de avaliação e aplicação de multas para corte irregular de árvores localizadas em vias públicas (Tabela 1), em acompanhamento ao trabalho dos funcionários da Secretaria Municipal do Meio do Ambiente, no Departamento de Pesquisa e Monitoramento - MAPM/SMMA, na Divisão de Fiscalização, responsável pelo licenciamento e atendimento de denúncias de corte irregular da vegetação. Para cada árvore avaliada foi anotada a espécie, a classe de diâmetro e estimada a sua idade (devido a sua não disponibilidade em banco de dados).

Tabela 1 - Casos reais selecionados para análise do valor das multas para corte irregular de árvores na cidade de Curitiba - PR

\begin{tabular}{|c|c|c|c|c|c|c|}
\hline № & NOME CIENTÍFICO & $\begin{array}{l}\text { NOME } \\
\text { VULGAR }\end{array}$ & ORIGEM & BAIRRO & $\begin{array}{l}\text { IDADE } \\
\text { (anos) }\end{array}$ & $\begin{array}{c}\text { CLASSE DE } \\
\text { DIÂMETRO } \\
(\mathrm{m})\end{array}$ \\
\hline 01 & Ligustrum lucidum Aiton & Alfeneiro & Exótica & Centro & 25 & $0,15-0,45$ \\
\hline 02 & Acer negundo L. & Acer & Exótica & Vila Isabel & 20 & $0,15-0,45$ \\
\hline 03 & Lafoensia pacari A. St.-Hil. & Dedaleiro & Nativa & Santa Quitéria & 4 & $<0,15$ \\
\hline 04 & Ligustrum lucidum Aiton & Alfeneiro & Exótica & Bairro Alto & 5 & $<0,15$ \\
\hline 05 & $\begin{array}{l}\text { Tipuana tipu (Benth.) } \\
\text { Kuntze }\end{array}$ & Tipuana & Nativa & Vila Hauer & 25 & $>0,45$ \\
\hline 06 & $\begin{array}{l}\text { Senna multijuga (Rich. H. } \\
\text { S. Irwin \& Barneby }\end{array}$ & $\begin{array}{l}\text { Cássia- } \\
\text { multijuga }\end{array}$ & Nativa & Boqueirão & 15 & $0,15-0,45$ \\
\hline 07 & $\begin{array}{l}\text { Parapiptadenia } \quad \text { rigida } \\
\text { (Benth.) Brenan }\end{array}$ & Angico & Nativa & Boqueirão & 9 & $0,15-0,45$ \\
\hline 08 & Lagerstroemia indica L. & Extremosa & Exótica & Xaxim & 15 & $<0,15$ \\
\hline 09 & Melia azedarach Blanco & Cinamomo & Exótica & Sítio Cercado & 27 & $>0,45$ \\
\hline 10 & Bauhinia variegata $\mathrm{L}$. & Pata-de-vaca & Exótica & Pinheirinho & 4 & $<0,15$ \\
\hline
\end{tabular}

Para todos os casos avaliados considerou-se que seria aplicada multa em valor integral, conforme o Código Florestal do Município (Lei no 9.806/2000), para a respectiva espécie e classe de diâmetro da árvore avaliada, conforme valores apresentados na Tabela 2. 
Tabela 2 - Valores das multas para corte irregular de árvores isoladas em bem público em Curitiba - PR

\begin{tabular}{lccc}
\hline ÁRVORES & $\mathrm{DC}^{1}<0,15 \mathrm{~m}$ & $\mathrm{DC}>0,15 \mathrm{~m} \mathrm{e}<0,45$ & $\mathrm{DC}>0,45 \mathrm{~m}$ \\
& & $\mathrm{~m}$ & \\
\hline Nativas & $180 \mathrm{UFIR}^{2}(\mathrm{R} \$ 190,80)$ & 700 UFIR $(\mathrm{R} \$ 742,00)$ & 1500 UFIR (R\$ 1590,00) \\
Exóticas & 120 UFIR (R $\$ 127,20)$ & 500 UFIR (R $\$ 530,00)$ & 1000 UFIR (R $\$ 1060,00)$ \\
\hline
\end{tabular}

FONTE: CURITIBA (2000)

NOTA: (1) DC = diâmetro do colo; (2) 1 UFIR = R \$1,0641

Os custos totais de implantação e manutenção capitalizados das árvores foram obtidos pela consulta aos valores calculados por Leal (2007), para as 22 espécies mais encontradas na cidade de Curitiba, conhecendo-se a idade e a espécie do indivíduo avaliado. Esta autora considerou cinco centros de custos, sendo estes: produção de mudas, plantio e replantio nas vias públicas, poda de árvores, remoção de árvores e planejamento e controle da arborização de ruas. Para estes centros de custos foram levantados os custos fixos, incluindo os juros sobre o capital investido, a depreciação e manutenção de equipamentos e benfeitorias e os salários fixos; e os custos variáveis, tais como: aquisição de insumos, materiais de consumo e despesas correntes com água, luz e telefone. Estes custos foram estratificados para nove grupos de espécies, formados de acordo com os custos de produção de mudas (em relação ao tempo de permanência de mudas em viveiro de espera que é variável com a taxa de crescimento - lento, moderado ou rápido) e aos custos das operações de poda e remoção (espécies de pequeno, médio ou grande porte).

\section{RESULTADOS E DISCUSSÃO}

Para todos os casos avaliados ( $n^{\circ} 1$ a 10), os valores estabelecidos pela legislação municipal da cidade de Curitiba foram inferiores aos custos de implantação e manutenção das árvores de rua (Tabela 3), sendo esta diferença proporcional à idade da árvore. $\mathrm{Na}$ avaliação de um indivíduo de Ligustrum lucidum com 25 anos de idade (caso no 1), os valores estabelecidos pela legislação municipal foram 22 vezes menores que os custos estimados de implantação e manutenção da arborização de ruas (ou aproximadamente 5\% dos custos). Mesmo na avaliação de uma árvore jovem, como um indivíduo de Ligustrum lucidum com cinco anos de idade (caso no 4), as multas seriam 10 vezes menores que os custos (aproximadamente 10\% dos custos). 
Tabela 3 - Valores das árvores de rua em casos reais na cidade de Curitiba - PR em 2006

\begin{tabular}{|c|c|c|c|c|c|}
\hline \multirow[t]{2}{*}{ № } & \multirow[t]{2}{*}{ ESPÉCIE } & \multicolumn{2}{|c|}{$\begin{array}{c}\text { VALORES DA } \\
\text { LEGISLAÇÃO MUNICIPAL }{ }^{1}\end{array}$} & \multicolumn{2}{|c|}{$\begin{array}{l}\text { CUSTOS TOTAIS DE IMPLANTAÇÃO } \\
\text { E MANUTENÇÃO DA ARBORIZAÇÃO² }\end{array}$} \\
\hline & & $\mathrm{R} \$$ & US\$ & $\mathrm{R} \$$ & US\$ \\
\hline 01 & Ligustrum lucidum & 530,00 & 244,46 & 11353,88 & 5237,03 \\
\hline 02 & Acer negundo & 530,00 & 244,46 & 7417,08 & 3421,16 \\
\hline 03 & Lafoensia pacari & 190,80 & 88,01 & 967,30 & 446,17 \\
\hline 04 & Ligustrum lucidum & 127,20 & 58,67 & 1308,19 & 603,41 \\
\hline 05 & Tipuana tipu & 1590,00 & 733,39 & 13502,69 & 6228,18 \\
\hline 06 & Senna multijuga & 742,00 & 342,25 & 4857,06 & 2240,34 \\
\hline 07 & Parapiptadenia rigida & 742,00 & 342,25 & 2599,81 & 1199,17 \\
\hline 08 & Lagerstroemia indica & 127,20 & 58,67 & 2803,84 & 1293,28 \\
\hline 09 & Melia azedarach & 1060,00 & 488,93 & 15217,12 & 7018,97 \\
\hline 10 & Bauhinia variegata & 127,20 & 58,67 & 642,52 & 296,36 \\
\hline
\end{tabular}

FONTE: (1) CURITIBA (2000), (2) LEAL (2007)

Os casos no 3 e 10, respectivamente indivíduos de Lafoensia pacari e Bauhinia variegata, ambos com a mesma idade estimada (quatro anos) e classe de diâmetro do colo $<0,15 \mathrm{~m}$, pela legislação municipal valeriam, respectivamente, $R \$ 190,80$ (origem nativa) e $\mathrm{R} \$ 127,20$ (origem exótica), enquanto pelos custos de implantação e manutenção da arborização de ruas valeriam $R \$ 967,30$ e $R \$ 642,52$ aos quatro anos.

Observa-se que os valores reais (custos de implantação e manutenção da arborização de ruas) diferem dos valores estabelecidos pela legislação municipal, sendo menores quando deveriam ser superiores a este. Os atuais valores das multas são apenas simbólicos. Isto significa que a população estaria pagando por prejuízos causados por terceiros, pois os valores da legislação não cobrem os custos para se ter uma árvore plantada em um dado local. Corroborando, para Detzel (1993), os custos de implantação e manutenção são o mínimo a ser ressarcido a prefeitura no caso de danos a uma árvore. Qualquer critério de redução do valor seria prejudicial, à medida que não permite a total cobertura dos gastos realizados com a arborização.

Ainda de acordo com Detzel (1992), quanto mais próximo da realidade for o valor estabelecido pela legislação, mais honestidade e justiça haverá em cada processo e menor será o risco de um questionamento jurídico por parte do infrator.

Segundo Milano e Dalcin (2000), os procedimentos de fiscalização só fazem sentido quando devidamente amparados em sistemática clara e objetiva de multas de valor real. Multas de valor simbólico não trazem resultados pelo simples fato de não implicar penalização real. Por sua vez, multas de valor real que carecem de clareza na interpretação de sua aplicação, ou não apresentem sustentação legal e objetiva, são questionadas judicialmente com sucesso e levam à desmoralização do procedimento.

Os resultados apresentados poderão subsidiar a reformulação da legislação vigente, com proposição de novo método de cálculo dos valores das multas. Por outro lado, verificase que, na prática, a cobrança de valores baseados nos custos totais de uma árvore muitas 
vezes seria impraticável pelos altos custos de implantação e manutenção da arborização de ruas. Segundo o Art. 42 da Lei 9.806/2000 (Código Florestal do Município), a autoridade deverá levar em conta a capacidade econômica do infrator na fixação do valor da multa, sendo que esta pode ser reduzida em até $90 \%$ do seu valor original (CURITIBA, 2000).

Mesmo que não se possa aplicar uma multa com os reais valores de uma árvore, a importância deste conhecimento enfatiza o valor da arborização urbana e da instituição responsável por ela. É muito importante que a população reconheça que a municipalidade faz muito mais por ela do que cobra por seus serviços. Isto demonstra que a instituição pública está administrando a cidade em favor ou em defesa do meio ambiente e da sua população.

A diferença entre os valores das multas e dos custos de implantação e manutenção de uma árvore poderá ser divulgada em campanhas de educação ambiental para a população conhecer os reais valores da arborização urbana. Para Detzel (1992) e Santos (1996), a valoração econômica das árvores urbanas será tanto maior quanto mais reconhecida sua importância.

\section{CONCLUSÕES}

Os valores das multas estabelecidas pela legislação municipal para o corte irregular de árvores de rua são inferiores aos custos de implantação e manutenção da arborização.

Devido aos altos custos de implantação e manutenção da arborização de ruas, a cobrança de valores das multas baseados nos custos totais de uma árvore seria impraticável, mas recomenda-se uma revisão dos valores cobrados devido ao fato de serem simbólicos em relação ao valor real total de uma árvore.

\section{AGRADECIMENTOS}

Ao Departamento de Pesquisa e Monitoramento da Secretaria Municipal de Meio Ambiente de Curitiba pelo fornecimento dos dados necessários para a realização deste trabalho.

\section{REFERÊNCIAS BIBLIOGRÁFICAS}

CURITIBA. Lei n 9806, de 03 de janeiro de 2000. Institui o Código Florestal do Município de Curitiba, e dá outras providências.

DETZEL, V. A. Arborização urbana: importância e avaliação econômica. In: CONGRESSO 
BRASILEIRO SOBRE ARBORIZAÇÃO URBANA, 1., 1992, Vitória. Anais... Vitória: Prefeitura Municipal de Vitória, 1992. p.39-52.

DETZEL, V. A. Avaliação monetária e de conscientização pública sobre arborização urbana: aplicação metodológica à situação de Maringá - PR. Curitiba, 1993. 84f. Dissertação (Mestrado em Engenharia Florestal) - Setor de Ciências Agrárias, Universidade Federal do Paraná.

GREY, G. W.; DENEKE, F. J. Urban Forestry. 2.ed. New York: John Wiley, 1986. 299p.

IPPUC. Curitiba em dados - 2006. Disponível em: <http://ippucnet.ippuc.org.br/bancodedados/curitibaemdados/curitiba_em_dados_pesquisa.a sp> Acesso em: 28 março 2007.

LEAL, L. Custos das árvores de rua - Estudo de caso: cidade de Curitiba - PR. Curitiba, 2007. 115f. Dissertação (Mestrado em Engenharia Florestal) - Setor de Ciências Agrárias, Universidade Federal do Paraná.

MILANO, M. S.; DALCIN, E. Arborização de vias públicas. Rio de Janeiro: Light, 2000. $226 p$.

OBA, L. T. Os marcos urbanos e a construção da cidade: a identidade de Curitiba. São Paulo, 1998, 327f. Tese (Doutorado em Estruturas Urbanas) - Faculdade de Arquitetura e Urbanismo, Universidade de São Paulo.

REIS, E. M. Informações fornecidas por Edélcio Marques dos Reis, Diretor do Departamento de Produção Vegetal da Secretaria Municipal do Meio Ambiente, Prefeitura Municipal de Curitiba, Curitiba/PR, 08 maio 2006.

SANTOS, E. Avaliação monetária de árvores urbanas: uma revisão. In: CONGRESSO NACIONAL SOBRE ARBORIZAÇÃO URBANA, 3., 1996, Salvador. Anais... Salvador: SBAU, 1996. p.140-150. 